\title{
Hepatoprotective and Anti-inflammatory Activities of Hydro-alcoholic Extract of Oxalis debilis Kunth. Leaves
}

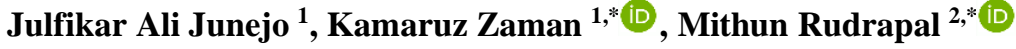 \\ 1 Department of Pharmaceutical Sciences, Dibrugarh University, Dibrugarh, Assam, India; jalijunejo@gmail.com (J.A.J.); \\ kzaman71@dibru.ac.in (K.Z.); \\ 2 Department of Pharmaceutical Chemistry, Rasiklal M. Dhariwal Institute of Pharmaceutical Education and Research, \\ Chinchwad, Pune, Maharashtra, India; rsmrpal@gmail.com (M.R.); \\ * Correspondence: kzaman71@ dibru.ac.in (K.Z.); rsmrpal@gmail.com (M.R.);
}

Scopus Author ID 36524068400

Received: 9.05.2021; Revised: 15.07.2021; Accepted: 19.07.2021; Published: 6.09.2021

\begin{abstract}
This study aimed to investigate hepatoprotective and anti-inflammatory activities of the hydro-alcoholic extract of Oxalis debilis (ODHE) leaves. Acute oral toxicity evaluated ODHE in graded oral doses $(100,500,1000,3000$, and $5000 \mathrm{mg} / \mathrm{kg}$ body weight) in rats. The hepatoprotective activity was evaluated in $\mathrm{CCl}_{4}$ intoxicated rats at 200 and $400 \mathrm{mg} / \mathrm{kg}$ body weight doses of ODHE, while antiinflammatory activity was determined by carrageenan-induced paw edema in rats at 200,400, 800 $\mathrm{mg} / \mathrm{kg}$ body weight doses of ODHE. The ODHE was safe at the highest dose of $5000 \mathrm{mg} / \mathrm{kg}$ in experimental rats. In hepatoprotective activity, ODHE significantly reduced the serum alanine aminotransferase (ALT), aspartate aminotransferase (AST), alkaline phosphatase (ALP), and total bilirubin (TB) levels as compared to the $\mathrm{CCl}_{4}$ control group. On the other hand, ODHE showed an antiinflammatory effect similar to that of the control group in the carrageenan-induced paw edema model. The histopathological findings showed a significant difference between the ODHE (400 mg/kg) and $\mathrm{CCl}_{4}$ groups. The present experiment showed that ODHE has significant hepatoprotective and antiinflammatory activities. Results confirm the use of $O$. debilis in folk medicine in the treatment of hepatotoxicity and inflammation.
\end{abstract}

Keywords: hepatoprotective; anti-inflammatory; ethnomedicine; hydro-alcoholic; Oxalis debilis.

(c) 2021 by the authors. This article is an open-access article distributed under the terms and conditions of the Creative Commons Attribution (CC BY) license (https://creativecommons.org/licenses/by/4.0/).

\section{Introduction}

Although still an unwritten science, herbal therapy is still an unwritten science. Herbal therapy is well established in some countries and traditions and has become a way of life in almost $80 \%$ of the population in rural areas. Chronic anti-inflammatory diseases, including rheumatoid arthritis, are still one of the main health problems of the world's population [1,2]. Although synthetic drugs dominate the market, the element of toxicity that these drugs entail cannot be ruled out. Their prolonged use may cause severe adverse effects on chronic administration, the most common being gastrointestinal bleeding and peptic ulcers [3].

Consequently, there is a need to develop a new anti-inflammatory agent with minimum side effects. Search for safe and effective anti-inflammatory agents have been given priority in scientific research in the herbal system of medicine. The liver plays a major role in regulating various physiochemical functions of the body, including synthesis, secretion, and metabolism of xenobiotics. Damage to the hepatic parenchyma may prove harmful to these physiochemical functions [4]. Many etiological factors may induce such damage, including infectious agents 
and hepatotoxic chemicals. In experimental animal studies, carbon tetrachloride (CCl4) is one of the most commonly used hepatotoxins for inducing liver injury $[5,6]$. The lack of effective modern medications for treating acute and chronic liver injury has led to research into the hepatoprotective activity of numerous medicinal plants using various experimental models.

Oxalis debilis Kunth. (Oxalidaceae) is a tristylous species native to Southern America and is a member of the bulb-forming shrub and distributed widely throughout the world. It is abundantly found in the Brahmaputra valley region of India [1]. The traditional uses of herbs and their extracts have been to cure human ailments since ancient times. It has been used traditionally for the treatment of dysentery and diarrhea [7]. A wide range of phytochemical constituents such as fatty acids, flavonoids, glycoglycerolipid, glycosides, phenol, phytosterols, tannins, and volatile oil has been reported from the leaves of the plant [8]. In modern literature, this plant species' antioxidant, anticancer, analgesic, antimicrobial, antiamoebic, antifungal, astringent, diuretic, and febrifuge activities have also been reported [9].

Ethnobotanical study indicates that leaf decoction of $O$. debilis has been used by tribal people of the North-eastern states of India for the management of liver disorders and inflammatory diseases [10]. There are no scientific reports in modern literature on the hepatoprotective and anti-inflammatory efficacy of $O$. debilis leaves. The objective of our present study was to ascertain the scientific basis of using this particular plant species traditionally in the management of liver disorder and inflammatory diseases and isolate phytoconstituents. According to WHO guidelines, the extract of $O$. debilis leaves was prepared using hydro-alcoholic solvent and evaluated for hepatoprotective and anti-inflammatory efficacy.

\section{Materials and Methods}

\subsection{Chemicals and reagents.}

All chemicals and reagents were of analytical grade and were procured from Rankem, Mumbai, and Himedia Laboratories Ltd., Mumbai. Commercial reagent kits used for the determination of biochemical parameters and enzymatic assays were purchased from SPAN Diagnostics Ltd., Surat (India). Silymarin was obtained from Quality Pharma Products Pvt. Ltd. Dibrugarh (India).

\subsection{Plant material.}

Fresh leaves of Oxalis debilis Kunth. were collected from forest areas of Dibrugarh district, Assam (India) during December 2014. The plant species were identified and authenticated (BSI/ERC/2014/Plant identification/360, dt. 26.08.2014) by Dr A. A. Mao, Scientist E, BSI, Eastern Regional Centre, Botanical Survey of India, Eastern Regional Centre, Shillong (India). A voucher specimen (DU/PSC/HRB/B-11/2014) of the identified plant species was deposited in the Herbarium of the Department.

\subsection{Preparation of hydro-alcoholic extract (ODHE).}

The air-dried leaves were coarsely powdered (Sieve no. 40) using a cutter mill, and 80 $\mathrm{g}$ of powdered leaves were used to prepare extract. Powdered leaves were extracted using sufficient quantity $(600 \mathrm{ml})$ of the ethanol-water mixture $(7: 3)$ by cold maceration for $24 \mathrm{~h}$. 
The extraction was carried out successively greatly, and the combined extract was then concentrated under reduced pressure to dryness in a rotary vacuum evaporator to obtain a thick semisolid-like paste. The crude extract was dried at $-40{ }^{\circ} \mathrm{C}$ in a lyophilizer, and the dried extract (dark brown color) so obtained was stored in a desiccator until further use. The percentage yield of the dried hydro-alcoholic extract (ODHE) was calculated per dry weight of powdered leaves.

\subsection{Test animals.}

Healthy Wistar male albino rats (240-260 g) were maintained under standard environmental conditions (temperature $25 \pm 2{ }^{\circ} \mathrm{C}$, relative humidity $50 \pm 5 \%$ ) with a $12 \mathrm{~h}$ light/dark cycle. They were fed on a normal laboratory chow pellet diet, and drinking water was given ad libitum. Animals were allowed to acclimatize for 7 days before the commencement of the experiment. The animals were used with the approval of the Institutional Animal Ethics Committee (Approval no. IAEC/DU/50 dt. 24.9.13) under guidelines set by the Committee for the Purpose of Control and Supervision of Experiments on Animals (CPCSEA), New Delhi (India).

\subsection{Phytochemical screening.}

Preliminary phytochemical screening [11-13] of the ODHE was carried out to detect the presence of various phytoconstituents like alkaloids, glycosides, flavonoids, phenolic compounds, tannins, saponins, proteins, amino acids, and steroids.

\subsection{Acute toxicity test.}

Health adult rats that were starved overnight were divided into six groups $(n=6)$. The rats were orally administered with increasing levels of dose concentration $(100,500,1000$, 3000 , and $5000 \mathrm{mg} / \mathrm{kg}$ ) of the plant hydro-alcoholic extract, and one group was kept as control. The animals were continuously observed for $4 \mathrm{~h}$ at an interval of $30 \mathrm{~min}$ under behavioral, neurological, and autonomic profile including toxicity and mortality, and then periodically after $6 \mathrm{~h}$ and then $24 \mathrm{~h}$ for any signs of acute toxicity up to 14 days [14].

\subsection{Hepatoprotective activity.}

Protocol previously described by Hussain et al. (2020) [15] was employed to determine the hepatoprotective activity. $200 \mathrm{mg} / \mathrm{kg}$ and $400 \mathrm{mg} / \mathrm{kg}$ of ODHE and standard drug silymarin $(100 \mathrm{mg} / \mathrm{kg})$ with saline and olive oil $(1 \mathrm{~mL} / \mathrm{kg})$ were administered 48, 24, and $2 \mathrm{~h}$ before induction of hepatic injury by $1 \mathrm{ml} / \mathrm{kg} \mathrm{CCl}_{4}$ (i.p) solution. Rats were divided into five groups; each group consisting of six animals.

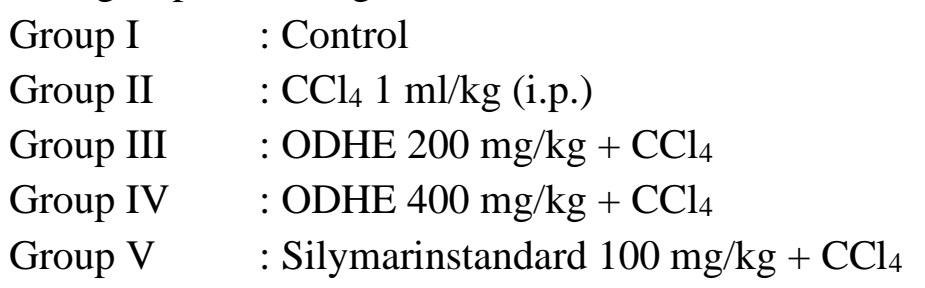

After 7 days the blood samples were collected from the rats, and biochemical analysis was done. Reitman and Frankel's [18] method was employed to determine serum aspartate aminotransferase (AST) and serum alanine aminotransferase (ALT) colorimetrically. Serum 
total bilirubin (TB) was determined by Jendrassik and Grof method, and serum alkaline phosphatase (ALP) activity was determined by King and Kings Method.

\subsection{Anti-inflammatory activity.}

Carrageenan induced paw edema model Paw edema was induced [16] by injecting 0.1 $\mathrm{ml}$ of $1 \% \mathrm{w} / \mathrm{v}$ carrageenan suspended in $1 \% \mathrm{CMC}$ into subplantar tissues of the left hind paw of each rat. Rats were divided into four groups; , each group consisting of six animals.
Group I : Carrageenan control
Group II : : ODHE $200 \mathrm{mg} / \mathrm{kg}$ )
Group III : ODHE $400 \mathrm{mg} / \mathrm{kg}$ )
Group IV : ODHE $800 \mathrm{mg} / \mathrm{kg}$ )
Group V : Indomethacin standard $(10 \mathrm{mg} / \mathrm{kg})$

The paw thickness was measured before injecting the carrageenan and after 60, 120, 180, 240, 300 min. using a vernier caliper. The anti-inflammatory activity was calculated as percentage inhibition of edema in the animals treated with extract under test compared to the carrageenan control group.

The percentage (\%) inhibition of edema is calculated using the formula:

$$
\% \text { inhibition }=\mathrm{T}_{\mathrm{o}}-\mathrm{T}_{\mathrm{t} / \mathrm{T}} \times 100
$$

where $T_{t}$ is the thickness of paw of rats given test extract at the corresponding time, and $T_{o}$ is the paw thickness of rats of the control group at the same time.

\subsection{Statistical analysis.}

Data were expressed as Mean \pm S.E.M (standard error of mean). Statistical analysis as performed by one-way analysis of variance (ANOVA) followed by Dunnett's comparison test to determine the degree of significance with a single normal and experimental control group. Plotting and normalization of the non-linear concentration-inhibition curve were done using GraphPad Prism 6.07 (GraphPad Software, Inc. version 5.0). The value of IC $_{50}$ was calculated from the normalized curves. The $p$-value less than 0.05 was considered statistically significant.

\section{Results and Discussion}

\subsection{Acute toxicity.}

Intensive observations on the animals treated with various doses of ODHE show no lethality or behavioral changes [17]. The experimented highest dose of $5000 \mathrm{mg} / \mathrm{kg}$ showed no toxicity and lethality at the end of the experiment.

\subsection{Hepatoprotective activity.}

A significant reduction in the production of the serum marker enzymes $(p \leq 0.001)$ was observed in $\mathrm{CCl}_{4}$ treated animals pre-treated with ODHE compared to the $\mathrm{CCl}_{4}$ treated control group. $\mathrm{CCl}_{4}$ treatment had no significant affect on the increase of ALP in the group pre-treated with $200 \mathrm{mg} / \mathrm{kg}$ ODHE and ALP and TB in the group pre-treated with $400 \mathrm{mg} / \mathrm{kg}$ ODHE. Further, the administration of $400 \mathrm{mg} / \mathrm{kg}$ ODHE reduces the serum marker enzyme activity almost close to the level observed in the group treated with silymarin (100 mg/kg) (Table 1).

The $\mathrm{CCl}_{4}$ treated animals also showed an elevated level of AST, ALT, and ALP Hepatic injury was sufficiently protected by ODHE. The normalization of the serum marker level may 
be due to the conditioning of hepatocytes by reverting the accumulation of the toxic bile salt in the liver cell, thereby maintaining the integrity of the membrane to check the leakage of the serum marker to the circulation [18]. AST is accompanied by an increase in ALT, which has a pivotal role in converting amino acids to keto acids. Biliary pressure increases the ALP synthesis, which increases its level [19]. The decrease in the serum marker enzyme in the study was found to be dose-dependent.

Table 1. Effects of ODHE on serum biochemical parameters in $\mathrm{CCl}_{4}$-intoxicated rats

\begin{tabular}{|c|c|c|c|c|c|}
\hline Group & Treatment & AST (IU/L) & $\operatorname{ALT}(\mathbf{I U} / \mathbf{L})$ & $\operatorname{ALP}(I U / L)$ & TB (mg/Dl) \\
\hline Group-I & Control & $142.16 \pm 7.78^{\# \#}$ & $77.33 \pm 6.05^{\# \#}$ & $225.16 \pm 9.02^{\# \#}$ & $0.14 \pm 0.01^{\# \#}$ \\
\hline Group-II & $\mathrm{CCl}_{4} 1 \mathrm{ml} / \mathrm{kg}$ (i.p.) & $602 \pm 19.19^{* *}$ & $492.16 \pm 18.65^{* *}$ & $426.16 \pm 7.91^{* *}$ & $0.32 \pm 0.01^{* * \# \#}$ \\
\hline Group-III & ODHE $200 \mathrm{mg} / \mathrm{kg}+\mathrm{CCl}_{4}$ & $322.66 \pm 13.96^{* * \# \#}$ & $\begin{array}{l}253.36 \\
\pm 10.39^{* * \# \#} \\
\end{array}$ & $259.33 \pm 6.46^{\# \#}$ & $0.24 \pm 0.04^{\# \#}$ \\
\hline Group-IV & ODHE $400 \mathrm{mg} / \mathrm{kg}+\mathrm{CCl}_{4}$ & $227.5 \pm 7.37^{* * \# \#}$ & $\begin{array}{ll}149.38 & \pm \\
8.91^{* * \# \#} & \\
\end{array}$ & $234.61 \pm 9.96^{\# \#}$ & $0.20 \pm 0.03^{\# \#}$ \\
\hline $\begin{array}{l}\text { Group-V } \\
*_{* *} p \leq 0.01\end{array}$ & $\begin{array}{l}\text { Silymarin } 100 \mathrm{mg} / \mathrm{kg}+\mathrm{CCl}_{4} \\
\text { s. control (Group I) }\end{array}$ & $193.5 \pm 34.19^{* * \# \#}$ & $82.16 \pm 30.94^{\# \#}$ & $229.83 \pm 15.81^{\# \#}$ & $0.17 \pm 0.02^{\# \#}$ \\
\hline
\end{tabular}

\subsection{Anti-inflammatory activity.}

Table 2 shows the effect of aqueous extract of leaves and standard drug compared to carrageenan control at different hours in a carrageenan-induced paw edema model using a vernier caliper. ODHE administered at a dose of $200 \mathrm{mg} / \mathrm{kg}$ p.o prevented carrageenan-induced paw edema with a percentage inhibition of $9.26 \%, 26.17 \%, 35.15 \%, 40.54$ and $46.90 \%$ at 1,2 , 3,4 and 5 hour, respectively, while $13.10 \%, 30.15 \%, 42.55 \%, 50.00 \%$ and $53.39 \%$, at a dose of $400 \mathrm{mg} / \mathrm{kg}$ p.o. at 1, 2, 3, 4 and 5 hour, respectively, while $17.06 \%, 31.95 \%, 45.68 \%, 58.44 \%$ and $64.83 \%$, at a dose of $800 \mathrm{mg} / \mathrm{kg}$ p.o. at 1, 2, 3, 4and 5 hour, respectively, Indomethacin at a dose of $10 \mathrm{mg} / \mathrm{kg}$ p.o. prevented carrageenan-induced paw edema with a percentage inhibition of $29.80 \%, 41.40 \%, 57.67 \%, 62.91 \%$, and $68.68 \%$ at $1,2,3,4$, and 5 hours, respectively.

Carrageenan-induced acute inflammation is one of the most suitable test procedures to screen anti-inflammatory agents. A biphasic curve generally represents the time course of edema development in the carrageenan-induced paw edema model in rats. The first phase of inflammation occurs within an hour of carrageenan injection and is partly due to the trauma of injection and also due to histamine and serotonin components [20, 21].

Table 2. Anti-inflammatory activity of ODHE on carrageenan-induced paw edema in rats.

\begin{tabular}{l|l|l|l|l|l|l} 
Group & $\mathbf{0}$ min & $\mathbf{6 0} \mathbf{~ m i n}$ & $\mathbf{1 2 0} \mathbf{~ m i n}$ & $\mathbf{1 8 0} \mathbf{~ m i n}$ & $\mathbf{2 4 0} \mathbf{~ m i n}$ & $\mathbf{3 0 0} \mathbf{~ m i n}$ \\
\hline $\begin{array}{l}\text { Group I: } \\
\text { Control }\end{array}$ & $0.563 \pm 0.016$ & $1.641 \pm 0.070$ & $1.884 \pm 0.047$ & $1.852 \pm 0.052$ & $1.766 \pm 0.039$ & $1.74 \pm 0.052$ \\
\hline $\begin{array}{l}\text { Group II: } \\
\text { ODHE 200 }\end{array}$ & $0.572 \pm 0.016$ & $1.489 \pm 0.027^{*}$ & $1.391 \pm 0.018^{*}$ & $1.201 \pm 0.016^{*}$ & $1.05 \pm 0.014^{*}$ & $0.924 \pm 0.047^{*}$ \\
\hline $\begin{array}{l}\text { Group III: } \\
\text { ODHE 400 }\end{array}$ & $0.555 \pm 0.019$ & $1.426 \pm 0.018^{*}$ & $1.316 \pm 0.027^{*}$ & $1.064 \pm 0.036^{*}$ & $0.883 \pm 0.012^{*}$ & $0.811 \pm 0.047^{*}$ \\
\hline $\begin{array}{l}\text { Group IV: } \\
\text { ODHE800 }\end{array}$ & $0.560 \pm 0.082$ & $1.361 \pm 0.021^{*}$ & $1.282 \pm 0.018^{*}$ & $1.006 \pm 0.016^{*}$ & $0.734 \pm 0.019^{*}$ & $0.612 \pm 0.012^{*}$ \\
\hline $\begin{array}{l}\text { Group V: } \\
\text { Indomethacin } \\
* p \leq 0.05\end{array}$ & $0.541 \pm 0.006$ & $1.152 \pm 0.048^{*}$ & $1.104 \pm 0.023^{*}$ & $0.784 \pm 0.033^{*}$ & $0.655 \pm 0.035^{*}$ & $0.545 \pm 0.021^{*}$ \\
$p$ & & & & &
\end{tabular}

As shown in Table 1, there was no significant inhibition of paw edema, 9.26\%, 13.10\%, and $17.06 \%$ in the early study hours by aqueous extract at 200,400 , and $800 \mathrm{mg} / \mathrm{kg}$, respectively. Hence, it can be concluded that there is no inhibition of histamine and serotonin. Carrageenan induced paw edema model in rats is known to be sensitive to cyclooxygenase 
inhibitors. It has been used to evaluate the effect of nonsteroidal anti-inflammatory agents, which primarily inhibit the cyclooxygenase involved in prostaglandin synthesis [22]. It plays a major role in developing the second phase of inflammatory reaction, which is measured at 3 hours. As shown in Table 2, there is a significant $(p<0.05)$ percentage inhibition of paw edema, $46.90 \%, 53.39 \%$, and $64.83 \%$ at 200,400 , and $800 \mathrm{mg} / \mathrm{kg}$ doses respectively, at 5 hours by the aqueous extract. Therefore, it can be inferred that the inhibitory effect of aqueous extract on carrageenan-induced inflammation may be due to inhibition of the enzyme cyclooxygenase leading to inhibition of prostaglandin synthesis.

\subsection{Histopatological examination.}

The liver sections from normal control animals (Group I) showed a classical structure with hepatocyte plates directed from the portal triads toward the central vein. The liver sections from the toxic control rats (Group II) showed massive changes throughout the lobules, with fatty accumulations, cellular vacuolization, and necrosis, as well as dilation of Disse spaces with focal disruption of the sinusoidal endothelium, inflammatory infiltrations of the portal triads, and distortion of the central venules. The pre-and post-treatment of animals with 400 $\mathrm{mg} / \mathrm{kg}$ hydro-alcoholic O. debilis leaves extract (Group IV) and silymarin $100 \mathrm{mg} / \mathrm{kg}$ (Group V) revealed milder hepatocellular vacuolation and better preservation of the normal liver architecture, with moderate hepatocyte plate disorganizations and smaller dilations of Disse spaces.
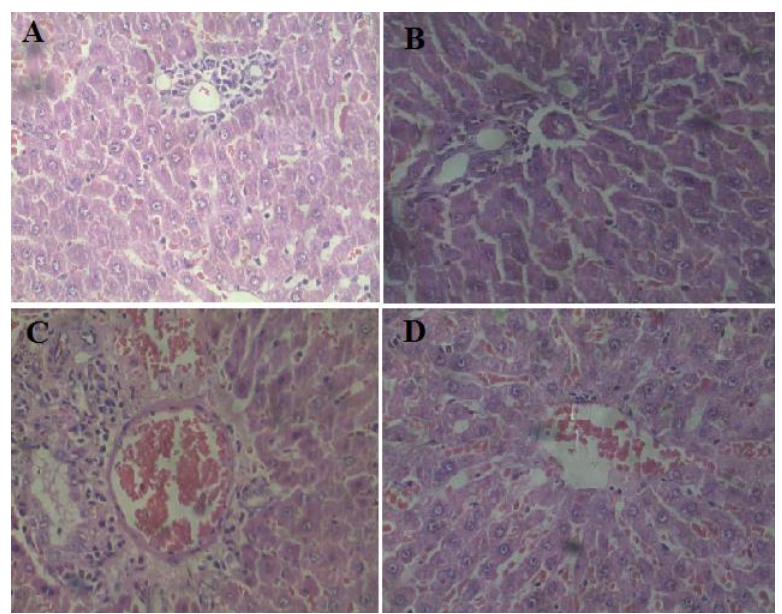

Figure 1. Photomicrographs of liver sections fixed in chilled 10\% saline buffer. (A) Group I - normal untreated; (B) Group II - $\mathrm{CCl}_{4} 1 \mathrm{ml} / \mathrm{kg}$ (i.p.) control; (C) Group IV - ODHE $400 \mathrm{mg} / \mathrm{kg}+\mathrm{CCl}_{4}$; (D) Group V -Silymarin $100 \mathrm{mg} / \mathrm{kg}$ as standard reference.

\section{Conclusions}

In the present study, the hydro-alcoholic leaf extract of Oxalis debilis (ODHE) restored the elevated serum enzyme levels. It counteracted the hepatic damage, suggesting that it has hepatoprotective, curative, and protective capacities in $\mathrm{CCl}_{4}$-intoxicated rats. The extract also showed to have potential anti-inflammatory activity. Results confirm their use in folk medicine in the treatment of hepatotoxicity and inflammation. In conclusion, ODHE needs further experimental approaches to explore its action mechanism and identify the active biomolecules, which will no doubt be a novel approach to treat different diseases. 


\section{Funding}

This research received no external funding.

\section{Acknowledgments}

\section{The first author is thankful to the University Grants Commission, Govt. of India, for providing financial support in a research fellowship.}

\section{Conflicts of Interest}

The authors declare no conflict of interest.

\section{References}

1. Junejo, J.A.; Rudrapal, M.; Mohammed, A.; Zaman, K. New flavonoid with antidiabetic potential from Tetrastigma angustifolia (Roxb.) Deb leaves. Brazilian J. Pharm. Sci. 2020, 56, http://dx.doi.org/10.1590/s2175-97902019000418806.

2. Hussain, N.; Kakoti, B.B.; Rudrapal, M.; Junejo, J.A.; Laskar, M.A.; Lal, M.; Sarwa, K.K. Anticancer and Antioxidant Activities of Cordia dichotoma Forst. Int. J. Green Pharm. 2020, 14, 265-273, http://dx.doi.org/10.22377/ijgp.v14i03.2940.

3. Corley, D.A.; Kerlikowske, K.; Verma, R.; Buffler, P. Protective association of aspirin/NSAIDS andesophageal cancer: A systemic review and meta-analysis. Gastroenterol. 2003, 124, 47-56, http://dx.doi.org/10.1053/gast.2003.50008.

4. Wolf, P.L. Biochemical diagnosis of liver disease. Indian J Clin Biochem 1999, 14, 59-90, https://doi.org/10.1007/BF02869152.

5. Johnston, D.E.; Kroening, C. Mechanism of early carbon tetrachloride toxicity in cultured rat hepatocytes. Pharmacol. Toxicol. 1998, 83, 231-239, http://dx.doi.org/10.1111/j.1600-0773.1998.tb01475.x.

6. Subramoniam, A., Pushpangadan, P. Development of phytomedicines for liver disease. Indian J. Pharmacol. 1999, 31, 166-175.

7. Luo, S.; Zhangi, D.; Renner, S.S. Oxalis debilis in China: Distribution of Flower Morphs, Sterile Pollen and Polyploidy. Ann. Bot. 2006, 98, 459-464, http://dx.doi.org/10.1093/aob/mcl121.

8. Junejo, J.A.; Zaman, K.; Rudrapal, M.; Hussain, N. Antidiabetic and Antioxidant Activity of Hydro-alcoholic Extract of Oxalis debilis Kunth. Leaves in Experimental Rats. Biosci. Biotech. Res. Comm. 2020, 13, 860867, http://dx.doi.org/10.21786/bbrc/13.2/71.

9. Panda, E.; Pradhan, C.; Das, A.B. Variations in phytoconstituents and antimicrobial activities in ecotypes of Oxalis corniculata L. and Oxalis debilis Kunth. Int. J. Pharm. Pharm. Sci. 2016, 8, 271-275.

10. Junejo, J.A.; Gogoi, G.; Zaman, K.; Islam, J.; Hazarika, G. Phytochemical profiling and toxicological studies of Oxalis debilis Kunth leaves. Int. J. Green Pharm. 2016, 10.

11. Junejo, J.A.; Rudrapal, M.; Zaman, K. Antidiabetic activity of Carallia brachiata Lour. Leaves hydroalcoholic extract (HAE) with antioxidant potential in diabetic rats. Indian J. Nat. Prod. Resour. 2020, 11, 1829, http://nopr.niscair.res.in/handle/123456789/54488.

12. Junejo, J.A.; Rudrapal, M.; Nainwal, L.M.; Zaman, K. Antidiabetic activity of hydro-alcoholic stem bark extract of Callicarpa arborea Roxb. with antioxidant potential in diabetic rats. Biomed. Pharmacother. 2017, 95, 84-94, https://doi.org/10.1016/j.biopha.2017.08.032.

13. Junejo, J.A.; Mondal, P.; Rudrapal, M.; Zaman, K. Antidiabetic assessment of the hydro-alcoholicleaf extracts of the plant Tetrastigma angustifolia (Roxb.), a traditionally used North-Eastern Indian vegetable. Biomed. Pharmacol. J. 2014, 7, 635-644, https://dx.doi.org/10.13005/bpj/535.

14. Hussain, N.; Kakoti, B.B.; Rudrapal, M.; Rahman, Z.; Rahman, M.; Chutia, D.; Sarwa, K.K. Antidiabetic Activity of the bark of Indian Cherry, Cordia dichotoma. Biosci. Biotech. Res. Comm. 2020, 13, 2211-2216, http://dx.doi.org/10.21786/bbrc/13.4/88.

15. Junejo, J.A.; Gogoi, G.; Islam, J.; Rudrapal, M.; Mondal, P.; Hazarika, H.; Zaman, K. Exploration of antioxidant, antidiabetic and hepatoprotective activity of Diplazium esculentum, a wild edible plant from North Eastern region of India. Future J. Pharm. Sci. 2018, 4, 93-101, https://doi.org/10.1016/j.fjps.2017.10.005.

16. Hussain, N.; Kakoti, B.B.; Rudrapal, M.; Sarwa, K.K. Anti-inflammatory and Antioxidant Activities of Cordia dichotoma Forst. Bark. Biomed. Pharmacol. 2020, 13, 2093-2099, https://dx.doi.org/10.13005/bpj/2090.

17. Onah, O.E.; Babangida, K.J. Phytochemical Investigation and Antimicrobial Activity of Hexane, Ethyl Acetate and Methanol Fractions from Stem Bark of Icacina trichantha Oliv (Icacinaceae). J. Chem. En. Sci. App. 2020, 7, 7-12, https://doi.org/10.15415/jce.2020.71002. 
18. Meharie, B.G.; Amare, G.G.; Belayneh, Y.M. Evaluation of Hepatoprotective Activity of the Crude Extract and Solvent Fractions of Clutia abyssinica (Euphorbiaceae) Leaf Against $\mathrm{CCl}_{4}$-Induced Hepatotoxicity in Mice. J. Exp. Pharmacol. 2020, 12, http://doi.org/10.2147/JEP.S248677.

19. El-Toumy, S.A.H.; Salib, J.Y.; Shafik, N.H.; Elkarim, A.S.A.; Salama, A.; Omara, E.A.A.; Micky, J. Evaluation of hepatoprotective activity of Polygonum equisetiforme methanolic extract. J. Appl. Pharm. Sci. 2019, 9, 054-059, http://doi.org/10.7324/JAPS.2019.91107.

20. Ondua, M.; Njoya, E.M.; Abdalla, M.A.; McGaw, L.J. Anti-inflammatory and antioxidant properties of leaf extracts of eleven South African medicinal plants used traditionally to treat inflammation. J. Ethnopharmacol 2019, 234, 27-35, http://doi.org/10.1016/j.jep.2018.12.030.

21. Villagómez-Rodríguez, A.; Pérez-Ramos, J.; Esquivel-Campos, A.L.; Pérez-González, C.; Soto-Peredo, C.A.; Pérez-Gutiérrez, S. Anti-inflammatory activity of Jefea gnaphalioides (a. gray), Astereaceae. BMC Complement. Altern. Med. 2019, 19, https://doi.org/10.1186/s12906-019-2654-X.

22. Phromnoi, K.; Sinchaiyakij, P.; Khanaree, C.; Nuntaboon, P.; Chanwikrai, Y.; Chaiwangsri, T.; Suttajit, M. Anti-Inflammatory and Antioxidant Activities of Medicinal Plants Used by Traditional Healers for Antiulcer Treatment. Sci. Pharm. 2019, 87, https://doi.org/10.3390/scipharm87030022. 